\title{
Acute myocardial infarction after administration of low-dose intravenous epinephrine for anaphylaxis
}

\author{
Kyle J. Shaver, MD; Christopher Adams, MD; Steven J. Weiss, MD
}

\begin{abstract}
This case describes a 29-year-old woman who presented with an acute severe anaphylactic reaction to penicillin. In addition to other medications administered in the emergency department, she received $0.1 \mathrm{mg}$ intravenously of 1:10 000 epinephrine, after which she immediately developed severe chest pain. Her ECG showed ST elevations consistent with an anterior myocardial infarction, and her serum troponin level was elevated. A CT angiogram showed no signs of coronary artery disease or abnormal anatomy. This case is an example of vasospasm-induced myocardial injury and illustrates a potential danger of intravenous epinephrine use. The authors were able to identify only 2 other case reports where therapeutic doses of epinephrine have been reported to cause this phenomenon.
\end{abstract}

Key words: variant angina; intravenous epinephrine; adverse drug effects

RÉSUMÉ

Le cas d'une femme de 29 ans victime d'une violente réaction anaphylactique à la pénicilline est décrit. En plus des médicaments administrés dans la salle d'urgence, la patiente reçut 0,1 mg de 1:10 000 d'épinéphrine intraveineuse après quoi elle manifesta une douleur intense à la poitrine. Son ECG révéla une élévation du segment ST correspondant à un infarctus du myocarde antérieur et son taux sérique de troponine était élevé. Un angiogramme CT ne révéla aucun signe de maladie coronarienne ni d'anomalie anatomique. Ce cas est un exemple de blessure myocardique provoquée par un spasme vasculaire et illustre le danger potentiel du recours à l'épinéphrine intraveineuse. Les auteurs furent en mesure d'identifier seulement deux autres observations ayant signalé que des doses thérapeutiques d'épinéphrine avaient causé un tel phénomène.

\section{Introduction}

Anaphylaxis is an acute medical condition that is often diagnosed and treated in the emergency department (ED). The use of epinephrine for severe anaphylaxis has been considered standard care for many years. The dose and route of administration is generally based on the severity of disease and the rapidity with which one wants to observe a response. Subcutaneous (SC) epinephrine is considered safe in patients who have no history of ischemic cardiac disease. In addition to $\mathrm{H}_{1}$ and $\mathrm{H}_{2}$ blockers and steroids, Salamone suggests epinephrine for signs of circulatory shock, but recommends an initial dose of $0.5 \mathrm{mg}$ of a 1:10 000 solution. ${ }^{1}$ Krauss, in an e-medicine article on anaphylaxis, states that epinephrine should be used in cases of severe anaphylaxis and lists routes as sublingual, SC or intravenous (IV). He suggested an IV dose of 0.1 $\mathrm{mg}$ of a 1:10 000 solution can be given slowly. ${ }^{2}$

Vasospastic angina is a rare condition, tending to occur at night or at rest, and is worsened by smoking. ${ }^{3}$ Relatively

\footnotetext{
Department of Emergency Medicine, University of New Mexico, Albuquerque, New Mexico

Received: Jan. 6, 2006; final submission: Apr. 10, 2006; accepted: May 15, 2006

This article has been peer reviewed.

Can J Emerg Med 2006;8(4):289-94
} 
few cases have been reported in the literature. ${ }^{4}$ In the case reported below, a patient received IV epinephrine for the treatment of severe anaphylaxis. This was followed immediately thereafter with the development of an acute myocardial infarction (AMI), presumably as a result of epinephrine-induced coronary vasospasm.

\section{Case report}

\section{Emergency department course}

A 29-year-old woman was prescribed penicillin $\mathrm{V}$ for pharyngitis by her primary care provider 2 days before ED presentation. On that same day she took 1 dose in the afternoon and a 2nd dose between 6 and $8 \mathrm{pm}$ that night, but denies taking any further doses during the day before presentation. In addition to the penicillin the patient had taken ibuprofen on several occasions in the previous 2-3 days for her sore throat. She denied having taken any other overthe-counter medications or prescription drugs, including oral contraceptives. She presented to the ED at approximately 1:45 am complaining of lip swelling and shortness of breath. Lip swelling commenced approximately 10 hours after the initial dose. Over the next 2-3 hours, the swelling continued to progress, involving her upper and lower lips, both eyes and cheeks. The shortness of breath developed during the hour before her arrival in the ED. She denied chest pain or pressure, dyspnea on exertion, cough or sputum production.

The patient denied any significant past medical history and had taken penicillin without problems in the past. She had no recent travel history and no new exposures or environments at work or at home. She denied a history of asthma, seasonal allergies, eczema or any previous history of facial swelling. There was no family history of early cardiac death, atopy, or diabetes in her parents or siblings. She admitted to occasional alcohol and tobacco use, but denied cocaine or other illicit drug use presently or in the past. A more complete review of systems was completed later in her course and revealed only the presence of a sore throat.

Physical exam revealed an anxious young woman in moderate respiratory distress. Initial vital signs were: temperature $36.7^{\circ} \mathrm{C}$, blood pressure $113 / 64 \mathrm{~mm} \mathrm{Hg}$, pulse 73 beats/min, respiratory rate $28, \mathrm{O}_{2}$ sat $94 \%$ on room air. She was sitting upright on the gurney and was unwilling to recline because it worsened her symptoms. She had extremely edematous eyelids narrowed to slits, swollen cheeks and protruding lips. The tongue was not enlarged, and there was no mucosal swelling in the oropharynx. She had no drooling, stridor or voice changes. Cardiovascular exam was normal. Her lungs were clear to auscultation. The rest of her exam was unremarkable, with no obvious rash.

Cardiac monitoring and pulse oximetry were initiated. Two large-bore IVs were placed, and oxygen via facemask was administered. Immediate medical treatment included diphenhydramine $50 \mathrm{mg}$ IV, methylprednisolone $125 \mathrm{mg}$ IV, and cimetidine $300 \mathrm{mg}$ IV. As she continued to be tachypneic and distressed, she was given 1:10 000 epinephrine, $0.1 \mathrm{mg}(1 \mathrm{cc}) \mathrm{IV}$. The dose was confirmed, as it was a preloaded 10 -cc syringe.

The patient's heart rate accelerated to greater than 160 beats/min. She began to complain of severe pressure-type central chest pain. Several ectopic beats were observed on the monitor. Although her heart rate declined to less than 100 beats/min within 5 minutes, she continued to complain of the chest pain.

Results of an ECG (Fig. 1) revealed ST elevation in leads I, avL, V2, and V5-6. There was ST depression in III, avF, and V1, correlating to reciprocal changes of anterolateral ischemia.

A first dose of sublingual nitroglycerin $0.4 \mathrm{mg}$ was administered with minimal effect. The patient also received $162 \mathrm{mg}$ of ASA. Her heart rate and blood pressure remained stable. She was then given 3 more doses of sublingual nitroglycerin over 10 minutes. With this, her pain decreased to 4/10. Figure 2 shows the results of her ECG at approximately that time: her ST segment changes had diminished throughout, although depressions in III and v1 were still present.

Because it was felt that vasospasm was the most likely cause, a nitroglycerin infusion was started and titrated up until she was pain free. Her blood pressure had decreased to approximately $90 / 35 \mathrm{~mm} \mathrm{Hg}$, so a normal saline infusion was started. She was now asymptomatic, with no complaints of lightheadedness, vision changes or chest pain. Her dyspnea had almost completely resolved. Figure 3 shows the improved results of her 3rd ECG, done 40 minutes after the initial one.

\section{Hospital course}

After ED stabilization, the patient was transferred to a monitored cardiac bed for further management. The patient's cardiac risk profile included occasional smoking and a positive family history of premature coronary artery disease (CAD); other risk factors were negative. Due to the patient's age, limited risk factors, the close correlation between her symptoms and the administration of epinephrine as well as the resolution of her symptoms and ECG changes with the administration of nitrates, the cardiology team concluded that plaque rupture was unlikely to be the etiology of the patient's symptoms. She was not anticoagulated, and received 
only 1 further dose of ASA. The rise in troponin (Table 1) is consistent with and diagnostic for an AMI in this setting.

After transfer to the cardiac unit her chest pain recurred, lasting approximately 1-2 hours. Repeat ECG demonstrated no recurrence of the initial ST segment abnormalities. The nitroglycerin infusion was titrated to relieve the

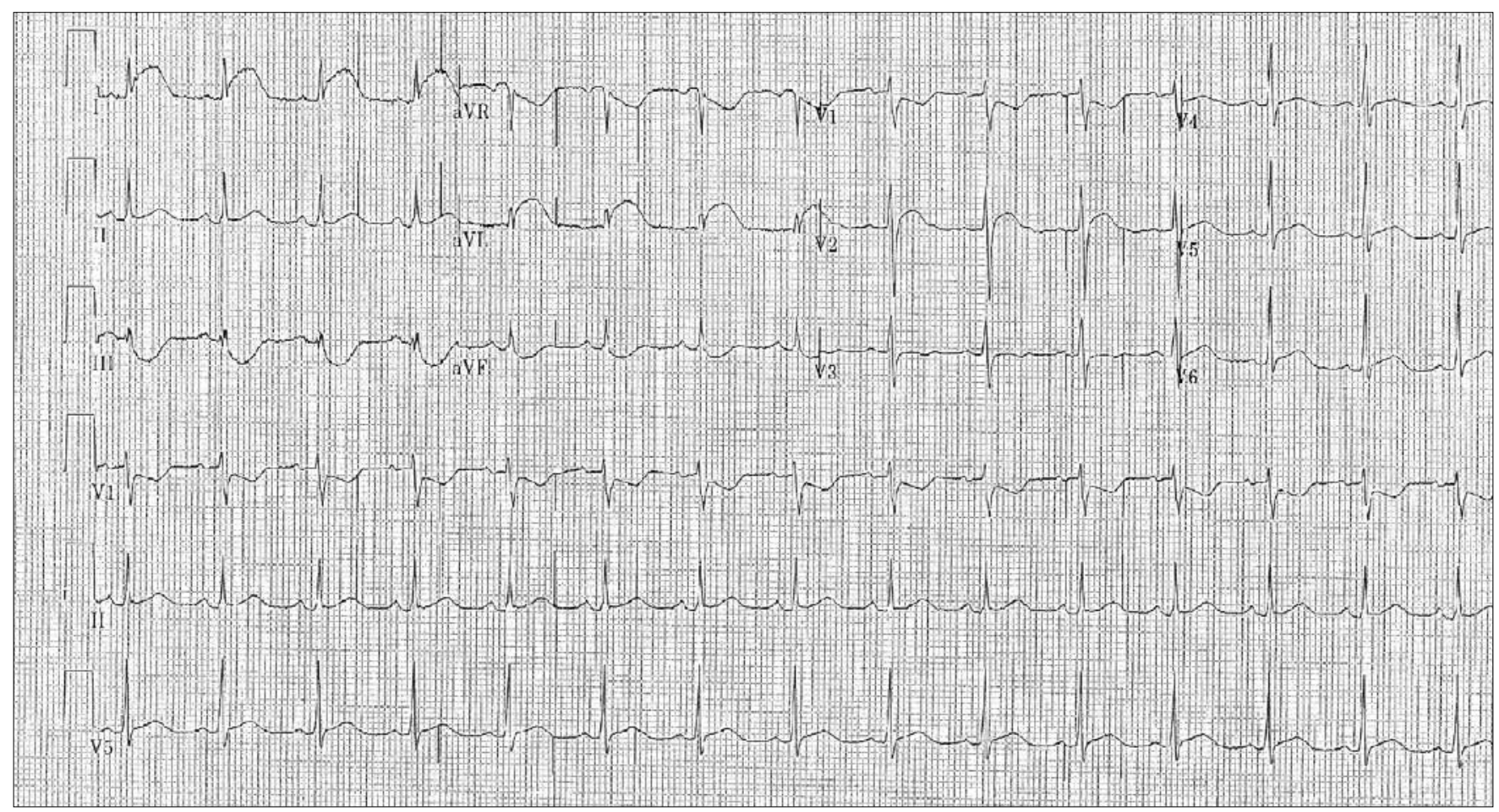

Fig. 1. Results of the ECG taken 5 minutes after epinephrine administration

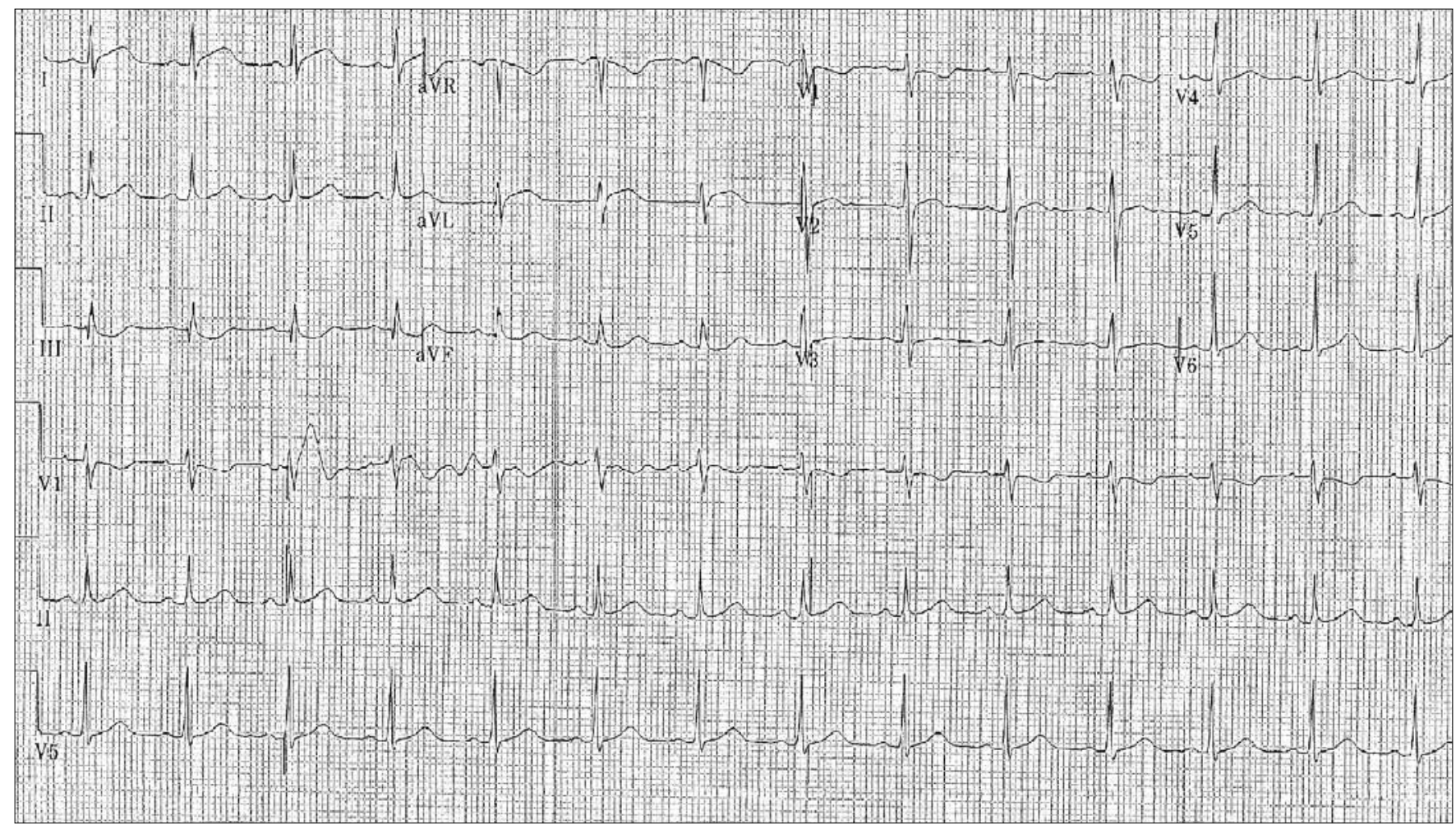

Fig. 2. Results of 2nd ECG. Resolving ST elevation as pain decreased; T-wave inversions and ST depressions in II and V1 still present 
chest pain, and morphine was also added. Additional boluses of normal saline were required to avoid further hypotension. Her anaphylaxis was managed with steroids and antihistamines without further complication.

The patient did not undergo coronary angiography. Since variant coronary anatomy can predispose young persons to ischemia, ${ }^{5}$ the patient had a CT-coronary arteriogram, which showed no evidence of variant anatomy or significant CAD, although it was a somewhat limited study. A transthoracic echocardiogram showed normal cardiac contractility, normal wall motion and no valvular abnormalities.

The patient was counselled on smoking cessation, and her medical therapy was transitioned from a nitroglycerin infusion to a long-acting calcium-channel blocker with sublingual nitroglycerin available for any recurrent chest pain. She was discharged home with those medications. The patient was seen in follow-up clinic approximately 3 weeks later and was still on her long-acting calcium-channel blocker. She had no recurrence of chest pain, had used none of her nitroglycerin, had no signs of congestive heart failure and had quit smoking.

\section{Discussion}

There have been several case reports of epinephrine-inducing coronary vasospasm, chest pain and arrhythmias. How- ever, the majority were from overdoses or operating room use. ${ }^{6,7}$ We searched PubMed for articles in the past 25 years, using various combinations of the search words (e.g., epinephrine, adrenaline, acute myocardial infarction, ischemia, anaphylaxis). We were only able to identify 3 cases of myocardial infarction associated when therapeutic doses of epinephrine were used for the treatment of anaphylaxis: 2 after SC injection and 1 after self-administration of epinephrine by way of an EpiPen ${ }^{\mathrm{TM}}$. $^{8-10}$

In the first case of SC injection, reported by Ferry and colleagues, ${ }^{8}$ a 43 -year-old man was given oral diphenhydramine for a rash and pruritus secondary to amoxicillin treatment for pharyngitis. When the patient did not show signs of improvement, 2 doses of 0.3-mg SC epinephrine were administered more than 1 hour apart. Fifteen minutes after the second dose, he developed an anterolateral MI,

\begin{tabular}{|c|c|c|c|}
\hline Time & $\begin{array}{l}\text { Troponin I } \\
(<0.04)\end{array}$ & $\begin{array}{l}\text { Creatine } \\
\text { kinase } \\
(20-212)\end{array}$ & $\begin{array}{l}\text { CK-MB } \\
(0-4.5)\end{array}$ \\
\hline 3:45 am & $<0.04$ & 66 & 0.1 \\
\hline 8:40 am & 1.99 & 85 & 3.3 \\
\hline 3:32 pm & 1.63 & 106 & 3.3 \\
\hline
\end{tabular}

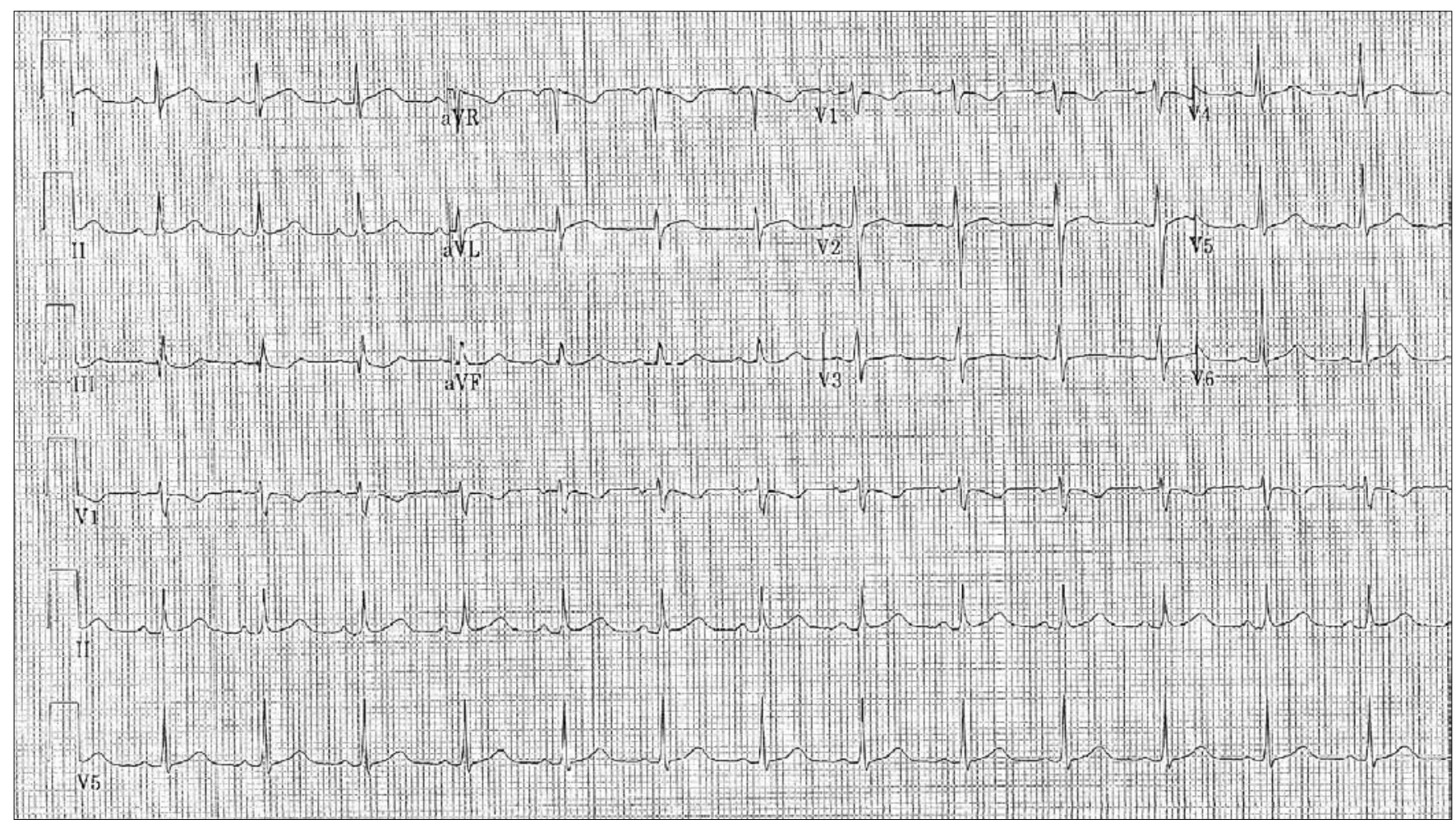

Fig. 3. Results of 3rd ECG. Resolving ST and T-wave changes 40 minutes after initial ECG and 17 minutes after the second ECG (Fig. 2) 
with ECG and marker changes. Subsequent catheterization showed normal coronaries on ECG.

Rubio Caballero and associates ${ }^{9}$ reported the case of a 41-year-old man with chest pain and ECG changes after administration of $0.5-\mathrm{mg}$ epinephrine SC that resolved spontaneously with administration of nitroglycerin. He also had normal coronary vasculature.

Saff and coworkers ${ }^{10}$ reported the case of a 30-year-old man who had used EpiPens in the past. On the day of admission, he used an epinephrine autoinjector for hives and wheezing secondary to a food allergy. Within 15 minutes he developed crushing substernal chest pain. His ECG showed acute changes, and his cardiac markers were elevated. The patient received thrombolytics, although subsequent catheterization showed only right coronary spasm that resolved after 2 sublingual nitroglycerin tablets.

Experimentally, epinephrine is known to induce spasm in susceptible patients, and has been used to diagnose variant type (or Prinzmetal's) angina. ${ }^{11}$ There have also been suggestions that patients with multiple risk factors for CAD may be more susceptible to complications of epinephrine injection. ${ }^{9}$ Most of the case reports, however, are in patients who are relatively young and without risk factors for MI, as was the case in this report.

The most likely cause of the patient's allergic reaction was the penicillin, even though ibuprofen has been (rarely) associated with an increased relative odds ratio of anaphylaxis. ${ }^{12,13}$ Based on definitions in the literature, any features suggesting respiratory involvement would be considered moderate anaphylaxis. ${ }^{14}$ The use of epinephrine was therefore warranted in this case.

Some authors have suggested that emergency physicians are not as aggressive as they should be with the use of epinephrine. ${ }^{15}$ Most documented adverse events have been associated with IV administration. ${ }^{16}$ Slow IV push epinephrine was felt to be safe because this patient had no evident contraindications. Gu and colleagues ${ }^{17}$ compared IV and intramuscular (IM) epinephrine in a rabbit model and found that IV epinephrine resulted in a peak plasma concentration of $3544 \mathrm{pg} / \mathrm{mL}$ at 5 minutes and IM epinephrine resulted in a peak plasma concentration of $7719 \mathrm{pg}$ at 32.5 minutes. The IM epinephrine peaked higher and later, suggesting that our patient may have had a more severe and prolonged cardiac reaction to IM epinephrine. This might also suggest that the IV route is not necessarily more dangerous than the IM one.

Opinions differ on the use of IV epinephrine for anaphylaxis. Brown and coworkers ${ }^{18}$ used it successfully in anaphylaxis secondary to insect stings. A recent symposium on the definition and management of anaphylaxis ${ }^{19}$ dis- cussed the use of all routes of epinephrine in detail, suggesting that IV epinephrine is an option in cases of severe hypotension and cardiac arrest. It is considered to be a preferred route in some cases where an IV line is in place (e.g., during surgery). The authors cautioned that potential lethal arrhythmias have been seen with IV epinephrine and encouraged careful monitoring. ${ }^{20}$ Their overall recommendation was to use IM epinephrine as the first-line route.

\section{Conclusion}

We have reported a case of an AMI in a young person with normal coronary arteries that occurred immediately after the administration of IV epinephrine for moderate anaphylaxis. Ultimately, this patient did well clinically and will likely not have any permanent sequelae. Physicians should be aware that in patients not at risk for ischemic heart disease, chest pain after epinephrine is most likely due to coronary artery vasospasm. Treatment should probably be limited to nitrates, even in the presence of an ECG that meets thrombolysis criteria.

Competing interests: None declared.

\section{References}

1. Salamone JA. Anaphylaxis and acute allergic reactions. In: Tintinalli JE. Emergency medicine: a comprehensive study guide. 4th ed. New York: McGraw Hill; 1996. p. 209-11.

2. Krauss R. Anaphylaxis [Internet]. 2005 Apr; Available: www .emedicine.com/EMERG/topic25.htm (accessed 2005 Dec 12).

3. Yasue H, Kugiyama K. Coronary spasm: clinical features and pathogenesis. Intern Med 1997;36:760-5.

4. Vandergoten P, Benit E, Dendale P. Prinzmetal's variant angina: three case reports and a review of the literature. Acta Cardiol 1999;54:71-6.

5. Mohlenkamp S, Eggebrecht H, Ebralidze T, et al. [Normal coronary angiography with myocardial bridging: a variant possibly relevant for ischemia.] Herz 2005;30:37-47.

6. Karch SB. Coronary artery spasm induced by intravenous epinephrine overdose. Am J Emerg Med 1989;7:485-8.

7. O-uchi J, Komukai K, Tohyama J, et al. Coronary artery spasm discovered in thorough examination of perioperative VT in a 26year-old Japanese male. Jpn Heart J 2003;44(6):1021-6.

8. Ferry DR, Henry RL, Kern MJ. Epinephrine-induced myocardial infarction in a patient with angiographically normal coronary arteries. Am Heart J 1986;111:1193-5.

9. Rubio Caballero JA, Oteo Dominguez JF, Maicas Bellido C, et 
al. [An adrenaline-induced vasospasm as the form of presentation of variant angina.] Rev Esp Cardiol 1999;52:273-6.

10. Saff R, Nahhas A, Fink JN. Myocardial infarction induced by coronary vasospasm after self-administration of epinephrine. Ann Allergy 1993;70:396-8.

11. Yasue $\mathrm{H}$, Touyama $\mathrm{M}$, Kato $\mathrm{H}$, et al. Prinzmetal's variant form of angina as a manifestation of alpha-adrenergic receptor-mediated coronary artery spasm: documentation by coronary arteriography. Am Heart J 1976;91:148-55.

12. van Puijenbroek EP, Egberts AC, Meyboom RH, et al. Different risks for NSAID-induced anaphylaxis. Ann Pharmacother 2002; $36: 24-9$

13. Takahama H, Kubota Y, Mizoguchi M. A case of anaphylaxis due to ibuprofen. J Dermatol 2000;27:337-40.

14. Brown SG. Clinical features and severity grading of anaphylaxis. J Allergy Clin Immunol 2004;114:371-6.

15. McLean-Tooke AP, Bethune CA, Fay AC, et al. Adrenaline in the treatment of anaphylaxis: What is the evidence? BMJ 2003; $327: 1332-5$
16. Davis. Allergies and anaphylaxis: analyzing the spectrum of clinical manifestations [Internet]. 2005 Oct. Available: www.EMPractice.net 7(10) (accessed 2005 Dec 12).

17. Gu X, Simons FE, Simons KJ. Epinephrine absorption after different routes of administration in an animal model. Biopharm Drug Dispos 1999;20:401-5.

18. Brown SG, Blackman KE, Stenlake V, et al. Insect sting anaphylaxis: prospective evaluation of treatment with intravenous adrenaline and volume resuscitation. Emerg Med J 2004;21: 149-54.

19. Sampson HA, Munoz-Furlong A, Campbell RL, et al. Second symposium on the definition and management of anaphylaxis: summary report - Second National Institute of Allergy and Infectious Disease/Food Allergy and Anaphylaxis Network symposium. J Allergy Clin Immunol 2006;117:391-7.

20. Karns JL. Epinephrine-induced potentially lethal arrhythmia during arthroscopic shoulder surgery: a case report. AANA J 1999;67:419-21.

Correspondence to: Dr. Steven Weiss, University of New Mexico, MSC 10 5560, 1 University of New Mexico, Albuquerque NM 87131-0001 